\title{
Rationality, strategic interactions, and theories of middle range
}

Social Science Information 2020, Vol. 59(4) 569-574

(C) The Author(s) 2020

Article reuse guidelines: sagepub.com/journals-permissions DOI: $10.1177 / 0539018420964390$ journals.sagepub.com/home/ssi

@SAGE

\section{Tobias Wolbring}

Friedrich-Alexander University Erlangen-Nürnberg, Germany

\begin{abstract}
Various versions of rational choice theories exist. In the face of common misconceptions of the approach, this comment aims to make two contributions. First, it informs about different variants and emphasizes the essential component of strategic uncertainty in game theory. Second, this article highlights the role of bridge assumptions when applying rational choice theories in practice. Hence, the rational choice approach is not a theory which can be directly applied in practice without further assumptions. Instead the rational choice approach is an analytical framework which leads to theories of middle range by combining a theoretical core with additional auxiliary assumptions which are tailor-made for a specific explanatory problem.
\end{abstract}

\section{Keywords}

bridge assumptions, game theory, macro-micro link, rational choice, situational analysis, theories of middle range, uncertainty

\section{Résumé}

Il existe diverses versions de la théorie du choix rationnel. Face à aux incompréhensions habituelles qui entourent cette approche, ce commentaire a pour but d'apporter deux contributions. Tout d'abord, il explicite quelles sont ces différentes variantes et souligne la composante essentielle de l'incertitude stratégique existant dans la théorie des jeux. Puis, cet article met en avant le rôle joué par les bridge assumptions, ou hypothèses passerelles lorsque les théories du choix rationnel sont mises en application. D'où le fait que l'approche qu'est le choix rationnel ne constitue pas une théorie qui puisse être directement mise en application sans d'autres hypothèses. L'approche du choix rationnel est plutôt un cadre analytique qui conduit à des théories de moyenne portée,

\footnotetext{
Corresponding author:

Tobias Wolbring, School of Business, Economics and Society, Friedrich-Alexander-University ErlangenNürnberg, Findelgasse 7/9, Nürnberg, 90402, Germany.

Email: tobias.wolbring@fau.de
} 
en combinant un noyau théorique avec des hypothèses auxiliaires supplémentaires qui sont faites sur mesure pour un problème explicatif précis.

\section{Mots-clés}

analyse situationnelle, choix rationnel, hypothèses passerelles, incertitude, lien macromicro, théorie des jeux, théories de moyenne portée

A common mistake of critiques of rational choice theories (RCT) is to conflate one specific - though historically important - version of the theory with the general analytical framework. In particular, it is a frequent misunderstanding that all theories of rational action rely on the same model of man - a homo economicus who is not only maximizing his or her individual net utility, but is fully informed, narrowly selfish, and solely focused on monetary costs and benefits. As scholars, chief among them Herbert Simon (1957), have pointed out time and again, this is obviously a quite narrow and demanding model of man which often lacks realism. This criticism of the homo economicus model has been well justified and important for the further development of RCT. However, it cannot serve as a justification for the general rejection of the whole analytical approach. While there are indeed many earlier RC models which are based on such assumptions of narrow self-interest, full information, and neglect of non-monetary incentives, numerous extensions and modifications exist which relax or drop some of the most unrealistic assumptions.

The article by Tibor Rutar (2020) contributes to this discussion in important ways. First, Rutar clarifies that the term 'rationality' is often falsely equated with 'rationality' in RCT. Rationality understood as 'intentional action' or 'acting for good reasons' is a more general concept which can serve as a useful theoretical starting ground for explanations in the social and behavioral sciences (see already Popper, 1962; Weber, 1978 [1921]). However, as noted earlier (Koertge, 1979), such a broad concept of rationality is more of a general guideline than a well-developed theory. To move from such a heuristic device to a testable and explanatory useful theory, the concept of rationality needs further specification.

Second, Rutar clearly highlights that RCT is not a theory but a family of theories which differ in their core assumptions. The often misunderstood concept of 'rationality' in RCT is thereby rather wide and has nothing to do with preference content and information conditions: 'the rationality assumption is nothing more than a consistency requirement' (Gächter, 2013: 35). In that sense, the type of rationality which Rutar calls 'responsiveness [of choices] to incentives' comes closest to the element that unifies the $\mathrm{RC}$ family. Different versions of RCT thereby differ with respect to a wider set of more or less strict assumptions about agents, in particular their decision rules, preferences, and information conditions which Rutar interprets as part of the concept of rationality.

Third, he emphasizes that this set of assumptions about agents can lead - Rutar claims necessarily will lead - to an at first glance counterintuitive trade-off between descriptive realism and explanatory usefulness. Adding layers of realism to a theory can negatively 
affect its tractability and precision and can complicate empirical tests. Thus, one should start with simple, parsimonious models and then carefully increase complexity.

Against this background, I would like to pick up two aspects in this comment which shine through in Rutar's article, but are not elaborated in the necessary detail that they deserve. The first point concerns the often strategic nature of decision making, also called strategic rationality in the literature. RCT can be broadly divided into two branches: (a) utility theory which deals with parametric decisions and (b) game theory which deals with socially interdependent situations of strategic interactions. The different versions of utility theory fit well into Rutar's classification of 'responsiveness to incentives', 'self-interested action', and 'full information'. In contrast to that, an important aspect - the strategic nature of social interactions - gets lost, I contend, when squeezing game theory into the proposed rationality typology.

Rutar assumes that game theory is 'one particular (mathematical) tool for applying a certain notion of rationality to a dynamic situation in which there are multiple agents who are acting strategically (i.e. are anticipating the actions of other agents to their actions)' (personal correspondence). Indeed, the major contribution of game theory was to develop tools to analyze strategic interactions, i.e. socially interdependent situations in which the payoff of one player not just depends on his or her decisions but also on the decisions of others.

Like in utility theory, agents act intentionally, respond to incentives, can be more or less selfish and are better or worse informed in game-theoretical models. However, the strategic nature of decision-making adds an important additional layer of complexity and realism which makes game theory a particularly useful tool for the social and behavioral sciences. Even if an agent is fully informed in a simultaneous game, a specific sort of uncertainty - strategic uncertainty - remains which is related to others' behavior and its consequences for individual payoffs. For example, in the volunteer's dilemma (Diekmann, 1985), every player wants that a person in need receives help. However, helping is costly and one helping player is sufficient to produce the socially efficient outcome. This leads to a diffusion of responsibility in a group of players or, in game-theoretic terms, a Nashequilibrium in mixed strategies in which the individual probability to help decreases with increasing group size.

This strategic uncertainty and how the player deals with it by forming rational or other expectations is, in my view, an important additional element in the conceptual toolbox and it helps to understand why and under which conditions individual rationality and collective rationality drift apart in social dilemmas such as the volunteer's dilemma.

Game theory thereby also offers a solution to another major problem of sociological theorizing including many applications of utility theory: the question of how individual actions aggregate to cause macro outcomes (Raub et al., 2011). While this micromacro link is obvious for some social phenomena such as crime or fertility rates, the transformation rule connecting the micro and the macro level can become more complex for others such as residential segregation and financial panics. Equilibria concepts in game theory, in particular the Nash equilibrium, offer one answer to the question of how individual actions have - sometimes unintended - consequences at the aggregate level. 
Talking about the Coleman boat and unintended consequences of rational action brings me to my second point: the macro-micro link, the essential role of bridge assumptions, and the idea that theories of rational action in practice often become theories of middle range. As Rutar (2019: 308) writes in another publication which is closely related to his article in Social Science Information:

RCT cannot be a general theory. It is rather a special theory, restricted to only certain domains of social phenomena. This observation is very much in line with the growing emphasis on middle-range theorizing in sociology that eschews developing grand theories that are general and unbounded. As is now well known social life is practically devoid of interesting universal causal laws which, had they existed, would allow grand theories to be applied. The move towards middle-range theories therefore shouldn't be all that surprising and can hardly be resisted.

While this statement contains many valid arguments about grand and middle-range theorizing, I beg to disagree that 'RCT cannot be a general theory'. RCT offers an analytical framework which is based on a common core. This core puts a special analytical focus on agents, which face opportunities and constraints, have preferences, and apply a decision rule which meets some consistency requirements. RCT - as every theory - has blind spots, but it can nonetheless serve as a rather general approach to provide insights into a wide range of different social and economic phenomena (e.g., Becker, 1990; Coleman, 1990). While I agree with Rutar that certain domains do not meet the scope conditions of RCT, the scope conditions of the analytical framework are still quite general. It can be even applied to areas which at first glance do not seem to have much to do with rational behavior such as addiction, religiosity, and social norms (e.g., Hechter \& Opp, 2005; Wittek et al., 2013). Thus, at this point I agree with Peter T. Leeson (2020) who contends in his comment that Rutar gives in too much to the critiques of RCT.

However, Rutar is right in emphasizing that the application of RCT to certain domains requires additional assumptions which do not directly follow from the theory itself. As elaborated by Siegwart Lindenberg (1992), so-called bridge assumptions connecting the macro and the micro level play an essential role to derive testable implications from RCT. For example, social science research has shown that the framing of a decision situation can have severe consequences for the salience of different goals. Similarly, behavioral game theory has documented that humans - under certain conditions - take non-narrowly selfish considerations such as on fairness, inequality, or revenge into account. At the same time, it seems that narrow RC models are not that bad in predicting the behavior of experienced agents in rather simple situations with sufficient incentives and competition (Binmore, 2007; Smith, 2008).

In other words, following the recommendation of Karl Popper (1962), scholars need to analyze the situation under investigation and, by adding further auxiliary assumptions, develop a tailor-made theory of rational action - a theory of middle range (Merton, 1968) which fits the decision context. In that spirit, one can argue that RCT is actually not a 'grand theory' but an analytical framework which structures and systematizes our theorizing in a certain way and draws scholars' attention to the actions of individuals which are embedded in social structures and cause - often unintended - macro outcomes. 
Tailor-made versions of the theory which are developed for certain domains can then be interpreted as theories of middle range with more limited scope conditions (see also Raub, 2017: 10).

As is well-known, even such a more moderate approach of middle range theorizing has its challenges and pitfalls. Additional assumptions should be introduced step-by-step and, at best, should be empirically corroborated or, at least, in principle testable. It is common sense among most rational choice theorists that, as a heuristic device, one should put priority to additional assumptions concerning opportunities, restrictions, and information conditions. Bridge assumptions thereby usually concern the macro-micro link and focus on the effects of social structures on individual opportunity structures. However, social structures and macro conditions can also influence individual preferences, but particular caution is needed when adding assumptions about preferences. Although wide versions of RCT, in principle, allow for non-selfish and non-monetary payoffs, such extensions pose the risk of adhocism and lacking empirical content. Since RCT itself is usually not of much help to justify such assumptions of how macro conditions affect individual opportunities and preferences, other theories and empirical findings are often used to derive bridge assumptions.

Despite all these challenges and pitfalls, RCT understood as a wide umbrella for a large family of middle-range theories is, I argue, an indispensable toolbox for understanding and explaining social and economic phenomena. By saying this, I go further than Rutar (2020) who contends that rationality 'should be seen as just one valuable tool of many in the theorist's explanatory "toolbox"'. RCT is not just one tool, but a quite versatile box containing many different tools. Situational analysis, bridge assumptions, and middle-range theorizing help to choose the right tool and combine it with the right attachments. It goes without saying that every tool and every toolbox have their limits. With a screwdriver and a hammer, you can do a lot but you can seldom fix a broken pipe. Then one should better call a plumber who brings other tools to fix the problem. But that doesn't mean that you want to dump the screwdriver and hammer, since you will almost certainly need these invaluable tools on another occasion.

\section{Acknowledgements}

I thank Peter Wagner for the opportunity to comment on Tibor Rutar's inspiring article.

\section{Funding}

The author received no financial support for the research, authorship, and/or publication of this article.

\section{References}

Becker GS (1990) The Economic Approach to Human Behavior. Chicago and London: The University of Chicago Press.

Binmore K (2007) Playing for Real. Oxford: Oxford University Press.

Coleman JS (1990) Foundations of Social Theory. Cambridge: Belknap Press.

Diekmann A (1985) Volunteer's dilemma. Journal of Conflict Resolution 29(4): 605-610. 
Gächter S (2013) Rationality, social preferences, and strategic decision-making from a behavioral economics perspective. In: Wittek R, Snijders TAB, Nee V (eds) The Handbook of Rational Choice Social Research. Stanford: Stanford University Press, pp. 33-71.

Hechter M, Opp KD (eds) (2005) Social Norms. New York: Russell Sage Foundation.

Koertge N (1979) The methodological status of Popper's rationality principle. Theory and Decision 10(1): 83-95.

Leeson PT (2020) One rationality to rule them all. Social Science Information 59(4).

Lindenberg S (1992) The method of decreasing abstraction. In: Coleman JS, Fararo TJ (eds) Rational Choice Theory: Advocacy and Critique. Newbury Park: Sage, pp. 3-20.

Merton RK (1968) Social Theory and Social Structure. New York: Free Press.

Popper KR (1962) The Open Society and Its Enemies, 4th ed. London: Routledge and Kegan Paul. Raub W (2017) Rational Models. Utrecht: Universiteit Utrecht.

Raub W, Buskens V, Van Assen M (2011) Micro-macro links and microfoundations in sociology. The Journal of Mathematical Sociology 35(1-3): 1-25.

Rutar T (2019) For an integrative theory of social behaviour: Theorising with and beyond rational choice theory. Journal for the Theory of Social Behaviour 49(3): 298-311.

Rutar T (2020) Varieties of 'rationality' and the question of their continued theoretical relevance. Social Science Information 59(4).

Simon HA (1957) Models of Man. New York: Wiley.

Smith VL (2008) Rationality in Economics. Constructivist and Ecological Forms. Cambridge: Cambridge University Press.

Weber M (1978 [1921]) Economy and Society. Edited by Guenther Roth and Claus Wittich. Berkeley: University of California Press.

Wittek R, Snijders TAB, Nee V (eds) (2013) The Handbook of Rational Choice Social Research. Stanford: Stanford University Press.

\section{Author biography}

Tobias Wolbring is a professor of economic sociology at Friedrich-Alexander-University ErlangenNürnberg and editor-in-chief of the German sociological journal Soziale Welt. He has published several books on economic sociology, higher education, and research methods as well as numerous articles in journals such as the European Sociological Review, Rationality \& Society, and Sociological Methods \& Research. 